Misleading by omission: rethinking the obligation to inform research subjects about funding sources

\begin{abstract}
Informed consent requirements for medical research have expanded over the past halfcentury. The focus here is upon one aspect of this expansion: the introduction of explicit obligations to inform subjects about funding sources, in the Declaration of Helsinki. Whilst it is agreed from the outset that a failure to inform about funding sources can wrong a research subject, a general obligation is problematic in a number of ways: including, determining the scope of the norm; plus problems with subjects' comprehension of complex funding information, and, most importantly, that such a norm seems to oblige researchers to disclose too much, including information irrelevant to most consent decisions. We ask whether the general obligation in Helsinki might be justified by appeal to respect for autonomy and informed consent, but find that it cannot be. The general obligation seems to rest upon an "informational fallacy". We then note that this orthodox justification of research ethics-by appeal to respect for autonomy and informed consent-has been subject to various critiques. The aim in the second part of the paper is to provide a better approach to making sense of how a failure to inform about funding sources wrongs subjects: making appeal to obligations to refrain from misleading by omission. This alternative approachgrounded in obligations to refrain from misleading-provides a basis for a norm that protects subjects interests without being hostage to the orthodox justification, that avoids the informational fallacy, and that-by and large-avoids the problems noted above about the scope of the obligation, and its implications for subjects' comprehension.
\end{abstract}




\section{Misleading by omission: rethinking the obligation to inform research subjects about funding sources}

\section{The Expansion of Informed Consent}

Over the past half-century, there has been considerable change in the governance of medical research. ${ }^{1}$ One aspect of this change has been the expansion of informed consent: researchers are required to disclose greater amounts of information of different kinds. ${ }^{2} \mathrm{~A}$ useful indicator of this expansion is the Declaration of Helsinki. Helsinki has undergone many revisions since 1964. ${ }^{3}$ In the 1964 original, the informed consent requirements are:

III.2 The nature, the purpose and the risk of clinical research must be explained to the subject by the doctor.

III.3a. Clinical research on a human being cannot be undertaken without his free consent after he has been informed

By 2000 — and unchanged in the most recent 2008 revision—we have a much wider informed consent requirement, to inform potential subjects of:

the aims, methods, sources of funding, any possible conflicts of interest, institutional affiliations of the researcher, the anticipated benefits and potential risks of the study and the discomfort it may entail, and any other relevant aspects of the study. ${ }^{4}$

Whilst some changes might be viewed as simply clarifying the original Helsinki requirements this is not the case for the requirement to inform subjects of "sources of funding" (and, similarly, "institutional affiliations of the researcher"). What we have here is as specification of new obligations to inform: to inform subjects about more aspects of research. This expansion of research ethics imposes costs, and may also pose risks: valuable research that is

\footnotetext{
${ }^{1}$ For example, rather than relying upon the integrity and virtues of researchers themselves, new bureaucracies and processes of governance have come into being to ensure good practice, including: the development of explicit codes of practice and requirements to gain approval from research ethics committees or institutional review boards. Ashcroft, Richard. "The ethics and governance of medical research: what does regulation have to do with morality?." New Review of Bioethics 1.1 (2003): 41-58.

2 There is a separate question here about the emergence of an obligation to ensure understanding, we shall not address that here, but see: Walker, Tom. "Informed consent and the requirement to ensure understanding." Journal of Applied Philosophy 29.1 (2012): 50-62; Sreenivasan, Gopal. "Does informed consent to research require comprehension?." Health Care Ethics in Canada (2011): 335.

${ }^{3}$ For a review of the changes see: Human D, Fluss SS. The World Medical Association's Declaration of Helsinki: Historical and Contemporary Perspectives http://www.wma.net/en/20activities/10ethics/10helsinki/draft historical_contemporary_perspectives.pdf

${ }^{4}$ Clause 26; http://www.wma.net/en/30publications/10policies/b3/ [Accessed $7^{\text {th }}$ December 2014]
} 
not pursued, or that is delayed. ${ }^{5}$ The expansion has, understandably, generated dissatisfaction and complaint from medical researchers. ${ }^{6}$ Of course, if the obligation to inform about funding is well-grounded, then the administrative burdens and costs (if proportionate) have to be borne and complaints about such burdens are not warranted. At this point is may seem simply obvious that research subjects ought to be informed of funding sources. Consider a simple example:

\begin{abstract}
Sue agrees, for altruistic reasons, to participate in a medical research project on the effects of smoking on health. She agrees to give her time, she agrees to permit certain kinds of (modest) intrusions upon her body, and to undertake certain risks (risks that are made known to her). However, the researchers do not disclose the fact that the research was funded by a 'Big Tobacco' corporation. Worse still, the corporation in question has a long history of funding research with the express purpose of generating "null findings" that could then be used to continue to sow doubt about links between smoking and cancer. ${ }^{7}$ Sue is vehemently opposed to such attempts to manufacture doubt and would never have consented had she known of the funding source. She feels anger and resentment. She feels duped. Her decision was misdirected, by another party for their own selfinterested ends. She may feel that her trust has been betrayed, and her diminishment of trust may expand beyond the individual researcher (or institution) to medical research more generally.
\end{abstract}

Suppose we agree that, in the context above, the research subject is wronged by the researchers' omission (we will say more below about why this is so). Suppose we also agree that research ethics codes of practice ought to include norms and requirements which help to ensure that this kind of wronging of research participants does not take place. The Helsinki requirement-if properly observed and followed by researchers, and by research ethics committees-would help to prevent this kind of wronging.

There are some familiar problems that arise at this point. What counts as a source of funding? If a cancer research charity funds research, but the charity receives a sizable percentage of its income each year from its association with a particular corporation (as part of its corporate social responsibility programme), is the corporation (ultimately) a "source of funding” that ought to be disclosed? What if two junior researchers are funded by a health

\footnotetext{
${ }^{5}$ McMahon, Alex D., et al. "The unintended consequences of clinical trials regulations." PLoS medicine 6.11 (2009): e1000131.

${ }^{6}$ Stewart, Paul, et al. "Regulation: the real threat to clinical research." BMJ. British medical journal 337.7678 (2008): 1085-1087;

E.g., see Michaels, David. Doubt is their product: how industry's assault on science threatens your health. Oxford University Press, 2008; Oreskes, Naomi, and Erik M. Conway. Merchants of doubt: how a handful of scientists obscured the truth on issues from tobacco smoke to global warming. Bloomsbury Publishing USA, 2010.
} 
charity, whilst the senior researcher is employed by a university, but the university receives money from a state funding body? For research that it is directly, or indirectly, totally or partly, funded by the state: is the taxpayer an ultimate "source of funding"? In complex economic systems, funding "chains" can be long and complex: should the whole chain be disclosed, or only part? If so, which parts?

A second problem concerns research subjects' comprehension: for many studies, funding sources may be manifold, and complex. Research subjects may not be able to comprehend such complex financial information. The researcher-and ethics committees-are placed in an unstable position: there is good reason to believe that information about funding sources will not be understood by research subjects, yet the research will be unethical—by Helsinki's standard - if it is not at the very least provided to subjects (this then raises the question: if the information will not be comprehended, why should that information be disclosed?).

One initial response to such worries is that they are nothing new. Regulation always involves questions of interpretation and implementation, and the problem of subjects' understanding is not restricted to financial information. Medical information more generally, can be complex and hard to understand, but researchers and research ethicists are well aware of this problem. ${ }^{8}$

However, there is a deeper problem. Whilst information about funding sources would be relevant in our "tobacco" example above, it does not follow from this that all information about funding sources is always of relevance to decisions to participate. In contexts where information about funding sources makes no difference to decisions to participate, it is unclear why researchers should be under any obligation to inform research subjects about those facts. After all, there is an indefinitely large body of information about research that would be of no relevance. So, our question is: is a general obligation to inform about funding sources justified?

In the first half of this paper we examine an orthodox approach to justifying the general obligation to inform about funding sources: an appeal to informed consent and respect for autonomy. But an appeal to informed consent and respect of autonomy does not does by itself support a general obligation to inform about funding sources. Indeed, it will be

\footnotetext{
${ }^{8}$ E.g., see: Flory, James, and Ezekiel Emanuel. "Interventions to improve research participants' understanding in informed consent for research: a systematic review." Jama 292.13 (2004): 1593-1601; Jefford, Michael, and Rosemary Moore. "Improvement of informed consent and the quality of consent documents." The lancet Oncology 9.5 (2008): 485-493; Lavori, Philip W., et al. "Improving informed consent in clinical trials: a duty to experiment." Controlled clinical trials 20.2 (1999): 187-193.
} 
suggested that there is a distinctive fallacy — a slippage in reasoning-involved in Helsinki's formulation of the requirement to inform about funding sources. Whilst it might seem that the obvious solution at this point is simply to "repair" the Helsinki formulation, in line with the orthodox justification-we face a second type of concern: the orthodox research ethics based on informed consent and respect for autonomy has, in recent years, been subject to various forms of critique.

In the second half of the paper the aim is to develop a way of thinking about the wronging in our example above that does not directly draw upon, or depend upon, the orthodox appeal to informed consent and respect for autonomy (at least in the first instance). By focusing on how omissions mislead, and how misleading omissions wrong audiences, we provide a basis for a norm that protects subjects interests without being hostage to the orthodox justification, that avoids the informational fallacy, and that-by and large-avoids the problems noted above about the scope of the obligation, and its implications for subjects' comprehension. ${ }^{9}$

\section{The orthodox argument: respect for autonomy, informed consent and the obligation to inform about funding sources}

Helsinki has its roots in a long international debate about the ethics of medical research following the Nuremberg trials and the awareness of Nazi research atrocities. The earlier Nuremberg Code-which sought to articulate what was wrong with the Nazi doctor's research abuses-places to the fore the requirement that medical research be consensual. Its first principle is: 'The voluntary consent of the human subject is absolutely essential'. Although Nuremberg does not refer to "Informed consent" by that name, it does implicitly make appeal to it, arguing that research is only permissible if the participant has:

sufficient knowledge and comprehension of the elements of the subject matter involved, as to enable him to make an understanding and enlightened decision. This latter element requires that, before the acceptance of an affirmative decision by the experimental subject, there should be made known to him the nature, duration, and purpose of the experiment; the method and means by which it is to be conducted; all inconveniences and hazards reasonably to be expected; and the effects upon his health or person, which may possibly come from his participation in the experiment.

\footnotetext{
${ }^{9}$ A recent paper by Bromwich and Millum addresses some of the concerns in this paper, focusing on how omissions might mislead (or be "fraudulent") in research recruitment. Bromwich and Millum's aims are different-they are not concerned with the expansion of informed consent, with the Helsinki obligation to inform about funding sources; their focus is more upon how focusing on misleading omissions reveals that disclosure requirements are separable from requirements to ensure understanding. Bromwich, Danielle, and Joseph Millum. "Disclosure and consent to medical research participation." J Moral Philos (2013).
} 
In the decades since Nuremberg bioethicists have argued that the obligation to "make known" certain aspects of the research is grounded, ethically speaking, in a fundamental liberal ethical requirement to "respect autonomy”. Here is a canonical formulation of this idea:

As a positive obligation [respect for autonomy] requires respectful treatment in disclosing information and fostering autonomous decision-making. [ . . .] Respect for autonomy obligates professionals in health care and research involving human subjects to disclose information, to probe for and ensure understanding and voluntariness, and to foster adequate decision-making. ${ }^{10}$

Medical researchers are under an obligation to ensure that "adequate" decisions are made, ones that are properly informed. Autonomy-based research ethics places obligations on researchers (and those engaged in ethical oversight of the research process, such as research ethics committees), to ensure that participation decisions are "adequate". This, in turn, is taken to underpin an obligation to disclose, and ensure understanding of, the kinds of information that is needed to make a "fully informed" or at least "adequately informed" decision.

The orthodox autonomy-based conception of research ethics provides us with the basis for an argument in favour of an obligation to inform about funding sources. Such an argument is developed by Martin Wilkinson: ${ }^{11}$

Unless subjects are informed of the researchers' personal characteristics, views, and sponsors whenever they would be likely to consider them significant, their autonomy is being overridden. ${ }^{12}$

Wilkinson assumes that ethically permissible participation requires a 'fully autonomous' decision (emphasis added) and in order to make a 'fully autonomous' decision a participant "would need to have disclosed to him all the true propositions that, if he believed them, he would consider for or against a given act or decision”. ${ }^{13}$

Thus I conclude that disclosure of those kinds of information can be important for subjects' autonomy and when it is, it is required by a concern for informed consent. It is not impractical to follow this criterion: disclose whatever potential subjects would consider significant. ${ }^{14}$

\footnotetext{
${ }^{10}$ Beauchamp, Tom L., and James Franklin Childress. Principles of biomedical ethics. Oxford university press, 2001. p. 64

${ }^{11}$ Wilkinson T M. Research, informed consent, and the limits of disclosure. Bioethics 2001;15:341-63.

${ }^{12}$ Wilkinson, op. cit. p. 363.

13 ibid. p. 346.

14 ibid. p. 347.
} 
Wilkinson refers to this as the autonomy-based disclosure standard: "disclose whatever potential subjects would consider significant”. ${ }^{15}$

One initial objection we might have to this line of argument is that it is an empirical matter whether or not information about funding is of relevance to research subjects. Some empirical studies suggest that potential subjects do not want to know about funding:

It would appear reasonable to conclude that providing information on the financial aspects of a trial generally is of little or no importance to patients. Their primary interest is whether they will benefit and whether they will be taking a serious risk. As expected, agreement to participate is directly related to poor control of the disease and a lack of alternatives. Patients who are newly diagnosed or those who are poorly controlled but have alternatives for therapy would probably not be particularly interested in financial data either. Their motivation, again, is primarily what they have to gain. ${ }^{16}$

But this study is small, and from 20 years ago. More recent studies suggest that subjects may now be more interested in such information than they were in Finkel's study. ${ }^{17}$ Suppose that there were good empirical data that many, or even most, potential research subjects want information about funding. Would this support the conclusion that there ought to be a requirement to proactively disclose such information?

A second problem with empirical studies is that we cannot infer from the fact that people (truthfully) say that they want information, that the information in question would be relevant to their decision-making about participation. Elsewhere I have written about this in the context of consent to clinical treatment, where it is clear that there are many reasons why patients want information, including information about proposed clinical interventions, other than that of deciding to consent. ${ }^{18}$ A patient may want information because the process of disclosure provides an assurance of trustworthiness (the content of the information is less important). Giving information also signals a kind of respect for the other party, again, independent of content. The patient wants to feel that she is being taken seriously, and communicated with, but may have already made up her mind to consent. Clearly there are important differences between decisions to consent to medical treatment and decisions to consent to participate in medical research. But the general point holds good: it is not at all

\footnotetext{
${ }^{15}$ ibid. p. 348. Note that Wilkinson's paper argues for requirements even more demanding than the 2008 revision of Declaration of Helsinki, including a requirement (in certain contexts) to disclose political and cultural attitudes, and even the views and prejudices of researchers.

${ }^{16}$ Finkel MJ. Should informed consent include information on how research is funded? IRB 1991;13:1-3. (p.3)

${ }^{17} \mathrm{Kim}, \mathrm{S}$. Y. H., et al. "Potential research participants' views regarding researcher and institutional financial conflicts of interest." Journal of Medical Ethics 30.1 (2004): 73-79.

$18 * *$ reference deleted $* * *$
} 
clear that we can infer from the fact that subjects want information-as part of the process of decision making - the conclusion that they thereby want that information in order to deliberate on the basis of the content of that information, and the ethical argument that we have before us is one where the obligation to inform subjects is based, not simply on their interests in gaining information, it is based on the relevance of that information for their decisions whether or not to participate in research.

But there is a further, much more basic, problem here: the autonomy-based argument does not justify the general obligation to inform about funding sources that we find specified in Helsinki.

\section{An informational fallacy}

Wilkinson's autonomy-based argument only justifies—and only aims to justify—a qualified, conditional obligation: researchers ought to disclose information about $\mathrm{X}$ to participants if (and insofar as) those participants would consider that information relevant to their decisions. In contrast, Helsinki specifies an unqualified obligation: researchers ought to disclose information about funding sources no matter what the subjects' knowledge or interests, including information that may be of no relevance at all to the subject's decisions.

Here is a diagnosis $s$ to what may be going on. When we consider examples like the "tobacco" situation outlined earlier, it is clear that information about funding can be relevant. Not only that, in order to avoid wronging the research participant, such information ought to be disclosed. But problems arise when we move away from these correct observations and intuitions and start to frame the issues in terms of either information about certain types of thing (in our current discussion: funding sources). This is simply a mistake. In our "tobacco" example, there is a "deal breaker" fact about the situation: the fact that the research is funded by a tobacco corporation. A deal breaker fact for an individual is a fact that, were it to be known by that individual, she would not decide to participate. ${ }^{19}$ On the autonomy-based line of argument we can justify a qualified obligation of the following kind:

(1) If it is the case that $p$, such that a potential research participant $\mathrm{R}$ would not participate in S's research were she to know that $p$;

and $\mathrm{S}$ knows that $p$;

\footnotetext{
${ }^{19}$ The "deal breaker" term used in the context of decisions to consent is borrowed from Tom Dougherty,. "Sex, Lies, and Consent*." Ethics 123.4 (2013): 717-744.
} 
and S is seeking R's informed consent to participate in S's research:

then $S$ ought to disclose the fact that $p$ to $\mathrm{R}^{20}$

This kind of principle specifies a norm for disclosing relevant information to research subjects, in line with Wilkinson's argument above. The illicit reasoning arises when we try to express this kind of norm in a simpler, general, way. Here it is tempting to specify a class of facts (or a type of information), and to introduce an obligation to inform "about funding sources”. The first step is that we recognise:

(2) $p$ is a fact of type $\mathrm{F}$

In our case the fact in question is a fact about funding sources . But it is a fallacy to make the inference from (1) coupled (2), to the conclusion:

(A3) S ought to disclose facts of type F

An analogy may help. Suppose we hold that states have a duty to protect their citizens. This duty generates a duty to inform about the risks posed by imminent severe storms. Information about imminent severe storms is information about the weather. But nobody would make the fallacious argument:

(i) The state ought to inform citizens about impending severe storms

(ii) Facts about severe storms are facts about the weather.

Therefore:

(iii) The state ought to inform citizens about the weather.

Part of the problem here, as I have argued elsewhere is that, thanks to deeply entrenched conduit and container metaphors that shape our talk about knowledge and its communication, there is tendency to view information as a kind of "stuff" that can be "disclosed" "broadcast" "shared" "given" "received" and so on. ${ }^{21}$ Whilst these metaphors do not give any rational support to the fallacious line of reasoning they, arguably, make it easier to adopt. By analogy, if we identify one piece of gold as malleable, or even as valuable, we can-unless

\footnotetext{
${ }^{20}$ This is an "objective" reading of a norm of disclosure grounded in principle that researchers ought to disclose information that is relevant to research participation. A "subjective" reading would add a third clause in the antecedent: “(iii) $\mathrm{S}$ believes that $\mathrm{R}$ would not participate were she to know that $p$ ”.

$21 * * * * *$ reference deleted $* * * * * * * * * * * * * * * * *$
} 
we have reason to think otherwise-judge that other pieces of gold will be malleable, and valuable. In thinking about funding sources, we begin by noting that in some contexts certain facts are of relevance in such a way as to ground obligations upon certain parties to communicate those facts to others. In communicating those facts we convey information of a certain type. It is then all too easy to slip to the conclusion that information of that type (about funding sources) is somehow — automatically_of ethical significance, and that there are thus obligations to convey information of that type, information about those things, no matter what. This "slippage” in reasoning, underpinned by certain metaphors, may explain why we end up with the current Helsinki requirement to inform "about funding sources". If so, this would also explain why we end up with the worries noted earlier about clarity, burdens, drawing limits, and so on.

\section{Taking stock: three options}

Let us take stock. Helsinki specifies a requirement to inform potential research subjects about funding sources, but is unclear in its scope, and faces questions about subjects' comprehension. Orthodox "autonomy and informed consent” based research ethics offers us a justification of a qualified obligation, but one that falls short of an obligation to inform about funding sources in general. The Helsinki requirement seems to involve a fallacious line of reasoning, one that takes us from the fact that information about funding sources can be of ethical relevance in some contexts to the conclusion that there is a general obligation to inform about funding sources no matter what.

The first option here would be to hold that (future revisions of) Helsinki should simply drop the requirement, without any need for something to replace it. But this is not an adequate response for in some cases-as in our tobacco example earlier-it seems that researchers ought to inform about funding sources, and, as such, this aligns information about funding sources (in those contexts) with information about the nature of the research, its risks and burdens and so on. At the very least we could do with a qualified obligation.

In light of this, a second option would be to stay with the orthodox autonomy-based research ethical framework and then seek to "repair" the Helsinki specification by introducing a qualified, restricted, obligation: for example, to inform research subjects about funding sources when they would be relevant. For those who favour the standard model of research ethics this would be the preferred option. 
However, the orthodox autonomy-based research ethics has, in recent years, been subject to a range of critiques. ${ }^{22}$ Alan Wertheimer, for example, argues that autonomy-based research ethics is improperly and unjustifiably "exceptional” in its demands for informed consent, rather than "simple" consent. ${ }^{23}$ Simple consent is a fundamental and important aspect of ethically sound and legally justified transactions in many different domains, including contexts where the decisions are of considerable importance, and contexts where consent poses risks to them. ${ }^{24}$ For example, many financial transactions are consensual but pose considerable risks. Indeed, the long term risks to a person's health of, say, losing all their money on a bad pension plan, might be much greater than the risks involved in taking part in a phase 3 clinical trial. Whilst there are regulations that apply to many transactions they are not as demanding as those that apply to medical research. People (consensually) buy items that they cannot afford, or that are worth little, but we do not hold that sellers ought to disclose everything about the item being sold. Or, consider sexual consent, individuals may have very strong views about the political orientation of those whom they have sex with. But there is no obligation, moral or legal, for an individual to proactively disclose his or her political orientation to potential partners. So why, then, should medical researchers be obliged to disclose information about institutional affiliation and sources of funding?

Wertheimer argues that medical research governance has, at its roots, the legitimate goal of protecting subjects from the kinds of force, deception and coercion that features in the alltoo-many "research atrocities" in the history of medical research. But protecting subjects from coercion, fraud and deception does not imply a positive obligation to "foster autonomy" or to proactively inform subjects about funding. Wertheimer argues that research governance has evolved in a paternalistic way. The positive obligation to "foster autonomy" serves to protect subjects, in their own best interests. If Wertheimer is right, then the autonomy-based argument viewed above is simply a symptomatic expression of the partly unjustified "exceptional” conceptual and normative framework that lies behind contemporary research ethics, a framework exemplified by Beauchamp and Childress’ Principles.

\footnotetext{
$22 * * *$ reference deleted********

${ }^{23}$ Alan Wertheimer. Rethinking the Ethics of Clinical Research: Widening the Lens: Widening the Lens. Oxford University Press, 2010. For similar contrastive claims about the clinical context, see Manson \& O’Neill Rethinking Informed Consent, and Onora O’Neill Autonomy and Trust in Bioethics. See also: Wendler, David. "What we worry about when we worry about the ethics of clinical research." Theoretical Medicine and Bioethics 32.3 (2011): 161-180; Sachs, Benjamin. "The exceptional ethics of the investigator-subject relationship." Journal of Medicine and Philosophy 35.1 (2010): 64-80.

${ }^{24}$ Wertheimer, pp. 75-84
} 
A second kind of critique of "autonomy and informed consent” research ethics is offered by Tom Walker. ${ }^{25}$ Walker calls into question the inferential links between a liberal requirement to respect others' autonomy, and an obligation to inform others. In research ethics, the positive obligation to inform, in Beauchamp and Childress' view, has its roots in respecting other agents as autonomous. But it cannot be, for example, autonomy as liberty that is the basis of this obligation. In classical liberal thought respect for liberty involves important and fundamental negative obligations: to refrain from interfering with others' lives, to refrain from force, fraud, coercion. ${ }^{26}$. Walker argues that other notions of respect for autonomy cannot directly generate this kind of positive obligation to inform. ${ }^{27}$ Suppose we take respect for autonomy to mean respect for the autonomous choices made by another agent. This tells us nothing about what we ought to do prior to that choice, and certainly does not generate a prior obligation to assist the agent in making her choice. Suppose we take respect for autonomy to mean something like respect for the agent's capacity to be autonomous. Once again, respecting another agent's capacity does not generate a positive obligation to develop her capacity, or to assist her in the exercise of that capacity. Finally, suppose we take respect for autonomy to mean something like respect for some kind of normative power, or sovereignty. Whilst this does generate an obligation to inform about proposed actions insofar as they would breach norms - e.g., norms of bodily integrity—it does not generate anything like a positive obligation to foster autonomous decision making.

If Wertheimer and Walker are correct, then there is a question mark against our second option: that of trying to "repair” Helsinki by making appeal to respect for autonomy and the orthodox doctrine of informed consent. We have not the space to fully evaluate Wertheimer and Walker's critiques here. In the remainder of this paper the aim is to develop a way of thinking about the wronging involved in our "tobacco" example that is acceptable to all, including those who accept, and those who are critical of, the "autonomy and informed consent” model of research ethics.

\section{Misleading and misdirecting}

In our "tobacco" example, Sue is misled. Now, lies and overt deception can mislead, but in our example she is misled by the researchers' omission. What is it to mislead by omission?

\footnotetext{
${ }^{25}$ Walker, Tom. "Respecting autonomy without disclosing information." Bioethics 27.7 (2013): 388-394.

${ }^{26}$ Berlin, Isaiah. Two concepts of liberty: An inaugural lecture delivered before the University of Oxford on 31 October 1958. Clarendon, 1959.

${ }^{27}$ Walker, Tom. "Respecting autonomy without disclosing information." Bioethics 27.7 (2013): 388-394.
} 
Because of the clear conceptual links to deception we might think that misleading is simply the inducing false beliefs in others. But there are two problems here. First, not all inducement of false beliefs mislead. If Sue is told by her sports-obsessed friend that Bari beat Modena two-nil in the campionato cadetto, and she believes him, even though it is false (the friend made a mistake). She has a false belief, but is not misled into deciding or doing anything on that basis. In contrast, had she taken that information and used it to bet against Modena's promotion prospects, she would have been misled. But, insofar as the friend simply made a mistake, the friend himself did not mislead Sue (one can be misled accidentally and unintentionally).

Second, it is not clear that misleading always requires the inducement of false beliefs. In our tobacco example, we do not need to assume that Sue forms a false belief-e.g., "this research is not funded by a tobacco company"-rather, what matters is her ignorance of a relevant fact. For example, if I give you a biscuit containing depleted uranium, you are misled into ingesting uranium, but it would be very odd to frame this in terms of inducing a false belief that the biscuit does not contain depleted uranium. ${ }^{28}$ But how can an absence play a role in shaping agency? There is nothing odd about making appeal to absences by way of explaining why things happen (“Their lack of a goalkeeper explains why they lost 25-0”). What such appeals do is say something like: the way things happened would have been different had it been the case that $p$, so the fact that it wasn't the case that $p$, helps us to understand why things happened as they did. In a similar way, there is nothing odd about appealing to ignorance in explaining why people acted in the way that they did.

Not all omissions are misleading. My failure to tell you what I had for breakfast need not mislead you, it simply leaves you in your current state of ignorance about that fact. Might this not count as misleading because the ignorance makes no difference to how you act? Suppose I have had an unusually large breakfast. You, ignorant of that fact, offer me a midmorning snack. Had you known of my large breakfast you would not have done so. But even though my omission makes a difference to how you act, you are not misled. Misleading comes into play when audiences have certain kinds of expectation.

\footnotetext{
${ }^{28}$ Philosophers of mind may argue that you have a tacit, or implicit, belief this biscuit does not contain depleted uranium (but once that move is made they have to accept that you have an indefinitely large set of such beliefs: this biscuit was never touched by Napoleon; this biscuit has not been to Alpha Centauri, and so, on and on).
} 
For example, suppose a group of soldiers are at rest, and appoint one of their company to stand guard. If the guard does not sound the alert, the soldiers are justified in inferring that there is no danger detected by the guard. Suppose the guard spots some wild game. Were the guard to have informed the company, they would have hunted the game for food. But the guard's silence does not mislead about the wild game. In contrast, suppose the guard is in fact a spy. The enemy approaches but the guard does not sound the alert. This omission, unlike the "game" omission, misleads the resting troop (not only do they act in a way that they would not, were they to be appraised of the facts, there is an expectation that they will be, and ought to be appraised of certain facts). Here there is a communicative expectation in play, of the form:

(1) If $\mathrm{S}$ knows that $p$ then $\mathrm{S}$ will make it known that $p$ to $\mathrm{R}$.

In our "guard" example, the resting soldiers adopt assumption (1) about the guard. The assumption is justified by a range of both normative and descriptive expectations about the role of "guard" together with expectations of trustworthiness and so on. But expectations of informing need not be tied to institutional contexts, or to playing particular special roles. For example, suppose you are driving to visit a friend, and, being lost, stop to ask a pedestrian how to get to your destination. "Do you know the area?” you ask. She affirms, and tells you a route. On arrival your host asks why you took such a long time. You explain your route. Your host is surprised. There was a much more direct route, and anyone who knew the area would know of it. Your "guide" did not explicitly lie to you. But she did mislead you by omission. You trusted the local to take your interests into account (and, unless otherwise specified, that would typically be to take the shortest route). On that basis you expect to be told of the most direct route (even if you do not ask for such a route directly).

Our "guard" and "local guide" example reveal that an additional assumption underpins misleading by omission. There is an implicit assumption of epistemic competence. If the soldiers believe that the guard will be roaring drunk by the time he is on duty his silence may not be informative. Similarly, if you assess the pedestrian — on the basis of her demeanour and speech, say —as being an unreliable source of information about the local area, you will not feel misled by her when she sends you the wrong way. Rather than framing it in terms of a failure to recognise your interests, and to then disclose a relevant fact (relevant against those interests), you frame it in terms of mere incompetence or ignorance: she does not know 
that there is a better route. In order to be misled by another party we have to make an assumption of competence:

(2) If it is the case that $p$ then $\mathrm{S}$ will know that $p$

The pairing of (1) and (2) provides a template for a very wide range of examples of misleading by omission. Misleading by omission will occur when an audience R assumes (1) and (2) in situations that have the following three features:

(3) It is the case that $p$

(4) R does not know whether it is the case that $p$

(5) S does not make it known that $p$ to R.

Note how (1) -(5) allows us to include misleading by maintaining ignorance and misleading by inducing false beliefs. S's failure to tell R that $p$, (given (4)) leaves her ignorant of that fact. However, if an agent assumes (1) and (2) she can infer from (5) that it is not the case that $p$ (e.g., one of our resting company of soldiers might form the belief "I am so glad the guard hasn't sounded the alert tonight, that means there are no enemies attacking”). But the misleadingness of the spy's act does not require the misled parties to form a false belief prior to acting.

In what way do misleading omissions wrong those who are misled? At this point there are many issues that arise with regard to the distinction between wronging and culpability, about responsibility and blameworthiness. For our current purposes, let us focus on knowingly misleading by omission. Knowingly misleading by omission

(i) S knows that $p$

(ii) $\mathrm{S}$ is in a position to tell $\mathrm{R}$ that $p$

(iii) $\mathrm{S}$ believes that $\mathrm{R}$ does not yet know that $p$ 
(iv) $\mathrm{S}$ recognises that $\mathrm{R}$ has a legitimate expectation that, if $\mathrm{S}$ knows that $p$, $\mathrm{S}$ will tell $p$;

(v) $\mathrm{S}$ believes that if $\mathrm{R}$ knows that $p \mathrm{R}$ will be more disposed to act in ways that are against $S$ 's interests, than if she remains ignorant of the fact that $p$.

Framed thus, intentional misleading involves deliberate misdirection of one agent's will in the service of another's. But this kind of control over another's will undermines her freedom. This is nicely captured in the following passage from Joseph Kupfer's analysis of what is morally wrong with lying:

Immediate restriction of the deceived's freedom is inherent in all (successful) lies because they limit the practical exercise of his reason: reasoning about possible courses of action. [. . . ] By limiting the horizon or content of his practical reasoning, the lie restricts the choosing and subsequent acting of the deceived. He reasons within a more or less false view of the world; misinformed, his practical conclusions and the actions they motivate are misdirected. ${ }^{29}$

Our discussion of misleading, and the expectations involved in it, suggest that Kupfer's points about how lying misdirects us, are applicable to misleading by omission. This also highlights a distinctive kind of wronging that is involved in misleading omission, one that brings us full circle back to orthodox bioethics. Misleading by omission involves a failure of respect for autonomy. ${ }^{30}$ Now, we noted, in Walker's critique of autonomy-based bioethics, that respect for autonomy can mean different things. We also noted Walker's scepticism about the way that respect for autonomy (in any plausible sense) might underpin an obligation to inform. Walker's scepticism may be appropriate if we are trying to find some route by which appeal to respect for autonomy, in the abstract, might ground a very broad obligation to inform (as the basis for informed consent, say). But our discussion of misleading by omission brings respect for autonomy into play in a more circumscribed, limited, way. If I do not tell you what I had for breakfast, even if that makes a difference to what you do, I am not intending to, or seeking to, influence or direct your behaviour. In contrast, in the "tobacco" example, the researcher is seeking to direct the research subject's behaviour, by maintaining her ignorance.

\footnotetext{
${ }^{29}$ Kupfer, Joseph. "The moral presumption against lying." The Review of Metaphysics (1982): 103-126.Kupfer acknowledges drawing upon Benn and Wenstein's theory of freedom: freedom as non-restriction of options. ‘Being Free to Act, and Being a Free Man’ S. I. Benn, W. L. Weinstein Mind, 1971 pp. 194-211

${ }^{30}$ Bromwich and Millum op. cit. offer a similar assessment of the way that misleading omissions undermine volutnariness: "When the researcher withholds information about a risk that she reasonably believes would be relevant to the prospective participant's enrolment decision, she arrogates his role as agent by determining what information he gets to consider. Her manipulation of the information he receives usurps his agency and thereby undermines the voluntariness of his decision”. p. 10.
} 
But doesn't this run us directly into the "exceptionalism” objection that Wertheimer raises about autonomy-based research ethics? People misdirect one another in many walks of life, but without the distinctive ethical and regulatory framework governing medical research? However, with regard to obligations not to mislead, it is arguable that such obligations are not especially “exceptional”. Obligations not to mislead are, arguably, more fundamental than informed consent requirements, and have a wide application in many types of everyday transaction outside medical research. For example, they feature in regulations governing advertising In the UK the Advertising Standards Authority's Code of Non-broadcast Advertising, Sales Promotion and Direct Marketing has the following requirements:

3.1 Marketing communications must not materially mislead or be likely to do so.

3.3 Marketing communications must not mislead the consumer by omitting material information. They must not mislead by hiding material information or presenting it in an unclear, unintelligible, ambiguous or untimely manner. ${ }^{31}$

The presence of such requirements does help to protect consumers, but rightly so. In a similar way, we should both expect and hope that research ethics codes of practice should protect research subjects. But the ASA's code of practice is nothing directly to do with "informed consent" nor is there any assumption that advertisers are under an obligation to "foster autonomy” or ensure "adequate" decision making. The obligations above are obligations to refrain from misleading, not positive obligations to disclose information of a certain type. Such regulatory codes play the role of protecting consumers from being misled into making purchases that they would not have made, had they been appraised of certain information in the possession of those advertising the goods in question.

\section{Conclusion: rethinking the obligation to inform about funding}

We began by noting the expansion of research ethics, more specifically, the expansion of informed consent requirements to include information about funding sources. We noted the burdens that this might impose, and concerns about clarifying which information ought to be disclosed, and worries about how complex financial information might be understood. But

\footnotetext{
${ }^{31}$ http://www.cap.org.uk/Advertising-Codes/Non-Broadcast/CodeItem.aspx?cscid=\{61a03caa-6750-498d-8732-

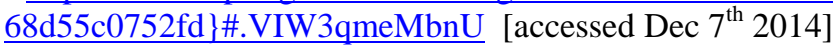


there was a much bigger problem: the obligation, as specified, is overly broad. Our "tobacco" example suggests that in some cases research subjects can be wrongfully misled. But we cannot infer from this that therefore information about funding no matter what ought to be disclosed. We turned to "orthodox" justifications of informed consent, grounded in respect for autonomy. Whilst this-via Wilkinson's argument-pointed us towards a line of argument that might justify an obligation to inform about funding sources in some contexts, there was still a large “gap” between Wilkinson's autonomy-based conclusion and what we find in Helsinki. We noted what seemed to be an "Informational fallacy" where there is an illicit inference from:

(1) If it is the case that $p$, $\mathrm{S}$ ought to inform $\mathrm{R}$

(2) $p$ is a fact of type $\mathrm{F}$

To the conclusion:

(3) S ought to inform R of type-F facts (no matter what)

At that point we then identified a number of options: the first was simply to drop the requirement from Helsinki. But examples like “tobacco”, plus evidence that subjects do have an interest in such information, suggests that this would be inappropriate. A second option was to do a "repair" job, keeping the orthodox autonomy-based approach. But this seemed to run into broader worries about autonomy-based bioethics and informed consent.

The third option was to step back and get clearer about the nature of the wronging in our "tobacco" example. In that example the researchers misled by omission. Misleading omissions misdirect the subject's decision in a way that disrespects her, in certain ways, as an autonomous agent. Now, it might seem that this simply brings us back to the autonomybased research ethics.

But here is a difference between the two approaches. On the orthodox informed-consent model, there is this background idea that decisions to participate in research are only "adequate" if they are made in a certain way: that they are based upon lots of information about the nature of the research, its risks, burdens, purposes and so on. But, as Wertheimer notes, lots of normatively efficacious decisions-to consent, to get married, to exchange contracts - are not made in this way. Wertheimer's response at this point is that we should 
move away from informed consent in research ethics. But there is another point here. The standard informed consent model puts it focus on the disclosure of certain kinds of information as the key material for decision-making. Although this approach does not entail anything like the Helsinki obligation to inform about funding sources, it does, arguably, provide a framework within which such a conclusion becomes thinkable. After all, if information is what research subjects need to make their decisions, surely the more information that they have, the better (provided it can be understood, and so on). The standard model in research ethics does not strictly entail the kind of expansion we have seen in Helsinki's informed consent requirements, but it may motivate it: more information is better.

But our approach has not made any assumption of this kind. Rather than focusing on classes of information-information about risks, the nature of the research, funding sources-we have been focusing on the ethically salient aspects of specific transactions. We have been focusing on what research subject's know, what they want to know, and, importantly, what they can reasonably and legitimately expect others to disclose to them, insofar as those others recognise and acknowledge the interests of research participants. The failing in the "tobacco" example is one where the researcher takes her own self-interest in securing research recruits to be of greater importance than disclosing certain facts about the research that, in that context, she has good reason to believe may be of relevance to them. But the proper regulatory response to cases of misleading by omission is to make explicit (and enforce, if necessary) the obligation to refrain from misleading, including misleading by omission. To introduce a general positive obligation to inform about certain types of topic is neither ethically required, nor defensible. ${ }^{32}$

Indeed, it is telling that in our UK Advertising Standard example, the ASA, wisely, do not attempt to specify the (many) possible "types of information" that need to be disclosed in order to avoid misleading. the Code notes, at 3.3:

Whether the omission or presentation of material information is likely to mislead the consumer depends on the context, the medium and, if the medium of the

\footnotetext{
${ }^{32}$ The discussion here is applicable to other aspects of the expanded Helsinki requirements. There is no general ethical obligation to inform research subjects about institutional affiliation, but it may be misleading, in some contexts, not to disclose institutional affiliation. This is the kind of consideration that can be assessed, on a case by case basis, in the institutional review process.
} 
marketing communication is constrained by time or space, the measures that the marketer takes to make that information available to the consumer by other means.

Here there is no general no positive obligation here to proactively disclose certain types of information or information about certain things to consumers (the notion of "making available" is much weaker). Also, there is no assumption that consumers ought to make their decisions in a particular way (one that requires large amounts of information about anything that may be of relevance). The approach taken by the UK Advertising Standards Authority shows that one can seek to protect people from being misled with something other than a requirement to positively disclose all information of a certain type, such as, information about funding sources.

One virtue of the approach here is that it does not imply an open ended obligation. This means that we avoid one aspect of the worry introduced at the start, that information about tax payers, about complex funding sources, and so on, might be included under the very general scope of "information about funding sources". On the approach developed here, it would (typically) not be misleading for a researcher to fail to disclose information that the research was funded by a cancer charity, or a university. There will always be questions of interpretation as to what might mislead, but given that research ethics involves numerous layers of "expert review" such problems seem to be no less surmountable than they are, say, in the regulation of advertising.

One further virtue of the approach developed here is that it should be acceptable both to those who stress the importance of respect for autonomy (we agreed that intentional misleading by omission is at odds with respect for the other as an autonomous agent); and to those-like Wertheimer and Walker-who are critical of the autonomy-based, informed-consent focused, conception of research ethics.

We have, then, a tentative proposal that (i) avoids the "overshoot" of Helsinki (ii) many of the problems about implementation; and (iii) critical concerns about the cogency and correctness of the standard "autonomy and informed consent" model of research ethics. On the proposal here we keep consent to the fore (as Helsinki always did). But rather than let a certain interpretation of respect for autonomy give rise to an open-ended "driver" of expansion (in the form of positive obligations to ensure that a certain kind of information-heavy decision is made) we should draw upon familiar, and robust, obligations to refrain from deception and misleading. Such obligations are context-sensitive, and whatever the difficulties in 
implementation, it seems clear that a more coherent, more defensible, less fallacious, and better grounded obligation is to be preferred to a less coherent, less defensible, more fallacious, and less-well grounded alternative: the current status quo, with its ill-specified, unjustified broad obligation to inform about funding sources in general. 